\title{
Formulation and Development of Fast Dissolving Oral Film of a Poorly Soluble Drug Piroxicam with Improved Drug Loading Using Mixed Solvency Concept and its Evaluation
}

\author{
Naveen Chaklan, R. K. Maheshwari, Garima Carpenter
}

Department of Pharmacy, Shri G.S. Institute of Technology and Science, Park Road, Indore, Madhya Pradesh, India.

Abstract

Aim: The aim of the present research work is to explore the application of mixed solvency to formulate and develop a fast dissolving oral film of piroxicam with improved drug loading utilizing the mixed-solvency concept. Materials and Methods: All solubilizers sodium benzoate, polyethylene glycol (PEG) 400, and polyvinylpyrrolidone (PVP) K30 were weighed accurately and transferred in a $100 \mathrm{ml}$ beaker. Then, warm and demineralized water sufficient to dissolve the solubilizers were added. After complete dissolution of solubilizers, $200 \mathrm{mg}$ of piroxicam was dissolved in the above solution, and temperature was maintained at $55-60^{\circ} \mathrm{C}$ so as to facilitate the evaporation of water. Then, this viscous mass was poured on the already prepared backing layer (having polymer ratio polyvinylalcohol [PVA] 14000: PVP K 30 [40:60] and 5\% w/w PEG 400 as plasticizer) in Petri plate and spread with spreader. The prepared film was dried in an oven at $40^{\circ} \mathrm{C}$ for $24 \mathrm{~h}$. The prepared films were kept in desiccators and used for further studies. Results and Discussion: On the basis of solubility studies, the blend containing PVP14000 + PEG 400 + SB (13.3:13.3:13.3) was selected. For formulation development, backing layer containing polymer ratio PVA 14000:PVP K 30 (40:60) was found to be most appropriate. PEG $4005 \% \mathrm{w} / \mathrm{w}$ provides faster dissolution of the prepared backing layer as well as better tensile strength. FD 8 batch showed better evaluation results and was taken as the optimized batch. Dissolution profiles of piroxicam pure drug, optimized fast dissolving oral film, fast dissolving oral film with perforations and marketed dispersible tablet (Pirox DT) were compared and results showed that dissolution rate of piroxicam from fast dissolving oral film was similar to marketed dispersible tablet (Pirox DT). Conclusion: From all the above studies, it was concluded that the approach of mixed solvency is novel, safe, cost-effective, and user-friendly. It also eliminates the problem of toxicity associated with high concentration of single solubilizers. Hence, it may be employed in dosage form development of drugs where fast onset of action is desired. It may also enhance the bioavailability associated with poor dissolution of drug.

Key words: Fast dissolving oral film, mixed solvency concept, piroxicam

\section{INTRODUCTION}

$\mathrm{F}$ Tast dissolving oral film, a new delivery system for the oral delivery of drugs, was developed based on the technology of the transdermal patch. Itconsists of a very thin oral strip, which releases the active ingredient immediately after uptake into oral cavity. In contrast to other existing, rapidly dissolving dosage forms, which mainly consist of lyophilizates; the fast dissolving film can be produced with the manufacturing process that is competitive with the manufacturing cost of conventional tablets. ${ }^{[1]}$
A huge number of different drugs can be formulated with this platform technology. Innovative products may increase therapeutic possibilities on the following indication:

\section{Address for correspondence: \\ Garima Carpenter, Department of Pharmacy, Shri G.S. Institute of Technology and Science, Park Road, Indore-452 003, Madhya Pradesh, India. \\ E-mail: garimac27@gmail.com}

Received: $31-05-2018$

Revised: 02-08-2018

Accepted: 19-08-2018 
Pediatrics (antitussive, expectorant, antiasthmatics, etc.), gastrointestinal disease and nausea (e.g., due to cytostatic therapy), pain (e.g., migraine), and CNS (e.g., ant parkinsonism therapy).

Fast dissolving oral film is a thin film, with an area of $5-10 \mathrm{~cm}^{2}$ containing an active ingredient. The immediate dissolution, in water or saliva, respectively, is reached through a special matrix from water-soluble polymers. ${ }^{[2-5]}$

A typical composition contains the following excipients:

\begin{tabular}{ll}
\hline Drug & $1-25 \%$ \\
Water-soluble polymers & $40-50 \%$ \\
Plasticizers & $0-20 \%$ \\
Fillers, colors, flavors, etc. & $0-40 \%$ \\
\hline
\end{tabular}

The fast-dissolving oral film can also be prepared by any one or combination of the following methods: ${ }^{[6]}$ Casting and solvent evaporation method, hot melt extrusion, solid dispersion extrusion, and coating method.

\section{Mixed solvency}

Maheshwari ${ }^{[7-29]}$ proposed the concept of mixed-solvency and proved that all substances whether liquids, solids, or gases may enhance the solubility of poorly soluble drugs. He has carried out solubility studies on poorly-water soluble drug salicylic acid (as a model drug). Solubility studies were carried in the solutions containing hydrotropic agents (urea and sodium citrate), cosolvents (glycerin, propylene glycol, and polyethylene glycol (PEG) 300 and PEG 400), and water-soluble solids (PEG 4000 and PEG 6000) individually as well as in 10 randomly prepared blends keeping total concentration constant, i.e., $40 \%$. Results showed that seven out of 10 blends produced a synergistic effect on solubility enhancement.

\section{MATERIALS AND METHODS}

\section{Materials}

Piroxicam drug was obtained as a gift sample from Shreya Life Sciences Pvt. Ltd., Aurangabad. Other chemicals used were of analytical grade. Demineralized water was used in the study.

\section{Preparation and optimization of backing layer}

For the preparation of backing layers (Table 1), about $50 \mathrm{ml}$ of $7.5 \% \mathrm{w} / \mathrm{v}$ aqueous solutions of individual polymers (polyvinyl alcohol [PVA] 14000 and polyvinylpyrrolidone [PVP] K 30) were prepared using magnetic stirrer (slight heating was required in case of PVA 14000). $20 \mathrm{ml}$ solutions of each polymer combinations were made by taking the volume of individual polymeric solutions. Glycerin was added as a plasticizer in all polymeric solutions $(5 \% \mathrm{w} / \mathrm{w}$ of total polymers). Then, volume of plasticized polymeric solutions was made up to $30 \mathrm{ml}$ with DM water to achieve polymeric concentration, $5 \% \mathrm{w} / \mathrm{v}$. Backing layers of different combinations of PVA 14000 and PVP K 30 were cast in plastic Petri plates ( $98 \mathrm{~mm}$ in diameter) as it provides about $20 \mathrm{mg}$ dry weight per $6 \mathrm{~cm}^{2}$. These casted films were dried in hot air oven at $40^{\circ} \mathrm{C}$ for $24 \mathrm{~h}$ and then stored in desiccator. These prepared backing layers were evaluated for their film properties, namely uniformity of thickness, dissolution time, folding endurance, hydration ratio, and tensile strength.

\section{Evaluation of backing layer}

\section{Uniformity of thickness}

Thickness of each prepared backing layers was measured using a micrometer (Digimatic Micrometer, Mitutoyo, Tokyo, Japan) with the sensitivity of $10 \mu$, at five locations (center and four corners), and the mean thickness was calculated. Samples with air bubble, nicks, or tears were excluded from such evaluation.

\section{In vitro dissolution time}

There may be some chances of polymeric residue of backing layers after complete dissolution of the drug deposit layer from bilaminated fast dissolving oral film. Hence, backing layers containing different polymer ratios of PVA 14000 and PVP K 30 were evaluated for in vitro dissolution time. This dissolution study was conducted in modified USP XXIII apparatus (paddle over disk) at $50 \mathrm{rpm}$, using $900 \mathrm{ml} 0.1$ $\mathrm{N} \mathrm{HCl}$ and $300 \mathrm{ml}$ simulated saliva fluid $\left(2.38 \mathrm{~g} \mathrm{Na}_{2} \mathrm{HPO}_{4}\right.$, $0.19 \mathrm{~g} \mathrm{KH}_{2} \mathrm{PO}_{4}$, and $8.00 \mathrm{~g} \mathrm{NaCl}$ per liter of distilled water adjusted with phosphoric acid to $\mathrm{pH} 6.8$ ) as dissolution media. The temperature was maintained at $37 \pm 0.5^{\circ} \mathrm{C}$. The time taken for complete dissolution of the polymeric backing layer was noted as the in vitro dissolution time.

\section{Determination of hydration ratio}

Hydration ratios of prepared backing layers were determined gravimetrically. The film sample $\left(6 \mathrm{~cm}^{2}\right)$ was weighed and placed on a pre-weighed stainless steel wire mesh with average sieve size opening of $200 \mu$. The screen was then submerged in a Petri dish containing $20 \mathrm{ml}$ DM water. Increase in weight of the film was determined at regular intervals until a constant weight was obtained. The hydration ratios of films were calculated according to the following equation:

Hydration ratio $=\frac{\mathrm{Wt}-\mathrm{W}_{0}}{\mathrm{~W}_{0}}$

$\mathrm{W}_{\mathrm{o}}=$ Weight of the film at zero time, and

$\mathrm{W}_{\mathrm{t}}=$ Weight of the film at time $\mathrm{t}$ 
Table 1: Composition of different polymeric combinations for backing layer

\begin{tabular}{lcccc} 
Backing layer & Polymer ratio PVA 14000: PVP K 30 & \multicolumn{2}{c}{ Volume of individual polymer solution (ml) } & Glycerin (mg) \\
\cline { 2 - 4 } & & PVA 14000 & PVP K 30 \\
\hline BL1 & $100: 00$ & 20 & - & 75 \\
BL2 & $80: 20$ & 16 & 4 & 75 \\
BL3 & $60: 40$ & 12 & 8 & 75 \\
BL4 & $40: 60$ & 12 & 16 & 75 \\
BL5 & $20: 80$ & 4 & 20 & 75 \\
BL6 & $00: 100$ & - & 20
\end{tabular}

PVA: Polyvinyl alcohol, PVP: Polyvinylpyrrolidone, PVA: Polyvinyl alcohol

\section{Table 2: Calibration curve of piroxicam in different media}

\begin{tabular}{lll} 
Media & Regression equation & Correlation coefficient \\
\hline D.M. water (at $358 \mathrm{~nm})$ & $\mathrm{y}=0.0417 x+0.0097$ & $\mathrm{R}^{2}=0.9997$ \\
Simulated Saliva fluid $(\mathrm{pH}$ 6.8) (at 358 nm) & $\mathrm{y}=0.0352 x+0.0252$ & $\mathrm{R}^{2}=0.9993$ \\
$0.1 \mathrm{~N} \mathrm{HCl}$ (at $333 \mathrm{~nm})$ & $\mathrm{y}=0.0777 x+0.0063$ & $\mathrm{R}^{2}=0.999$ \\
\hline
\end{tabular}

Table 3: Composition of different polymeric combinations for backing layer

\begin{tabular}{lcccc} 
Backing layer & Polymer ratio PVA14000:PVPK 30 & \multicolumn{2}{c}{ Volume of individual polymer solution (ml) } & \multirow{2}{*}{ Glycerin (mg) } \\
\cline { 2 - 4 } & & PVA 14000 & PVP $\mathbf{3 0}$ & 75 \\
\hline BL1 & $100: 00$ & 16 & 4 & 75 \\
BL2 & $80: 20$ & 12 & 8 & 75 \\
BL3 & $60: 40$ & 12 & 8 & 75 \\
BL4 & $40: 60$ & 4 & 16 & 75 \\
BL5 & $20: 80$ & - & 20 & 75 \\
BL6 & $00: 100$ & & & \\
\hline
\end{tabular}

PVA: Polyvinyl alcohol, PVP: Polyvinylpyrrolidone, PVA: Polyvinyl alcohol

\begin{tabular}{lcc}
$\begin{array}{l}\text { Table 4: In vitro dissolution time of prepared backing } \\
\text { layers }\end{array}$ \\
$\begin{array}{l}\text { Backing } \\
\text { layers }\end{array}$ & \multicolumn{2}{c}{ Dissolution time (min) } \\
\hline $\begin{array}{l}\text { Batch } \\
\text { no }\end{array}$ & $\mathbf{0 . 1 ~ H C l ~ ( m i n )}$ & $\begin{array}{c}\text { Simulated saliva } \\
\text { fluid (pH 6.8) (min) }\end{array}$ \\
\hline BL1 & More than 5 min & More than 6 \\
BL2 & $3-4$ & $3-4$ \\
BL3 & $2-3$ & $2-3$ \\
BL4 & $<1$ & $<1$ \\
\hline
\end{tabular}

\section{Folding endurance}

For determination of folding endurance, three films of each composition of size $6 \mathrm{~cm}^{2}(2 \mathrm{~cm} \times 3 \mathrm{~cm})$ were cut using sharp blade. Folding endurance was determined by repeatedly folding a small strip of film at the same place till it broke. The number of times, the film could be folded at the same place without breaking gave the value of folding endurance. The mean value of three readings and standard deviation was obtained.

\section{Tensile strength}

Tensile strength of the prepared backing layers was evaluated using tensile strength tester equipment equipped with a 50-kg load cell (Fibratech, Rookree). Backing layer in the dimension of $50 \mathrm{~mm} \times 10 \mathrm{~mm}$ and free from air bubbles or physical imperfections were held between two clamps positioned at a distance of $3 \mathrm{~cm}$. During measurement, the strips were pulled by the lower clamp at a rate of $2.0 \mathrm{~mm} / \mathrm{s}$ to a distance of $10 \mathrm{~cm}$. The force was measured when the films were broken.

\section{Selection of plasticizer}

For the selection of plasticizer, three batches of backing layers were prepared with a fixed concentration $(10 \% \mathrm{w} / \mathrm{w}$ of polymer) of three different plasticizers, namely propylene glycol, glycerin, and PEG 400 taking polymer combination PVA 14000:PVP K 30 (40:60). All three prepared batches were studied for the evaluation parameters, namely thickness, dissolution time, folding endurance, and tensile strength. 


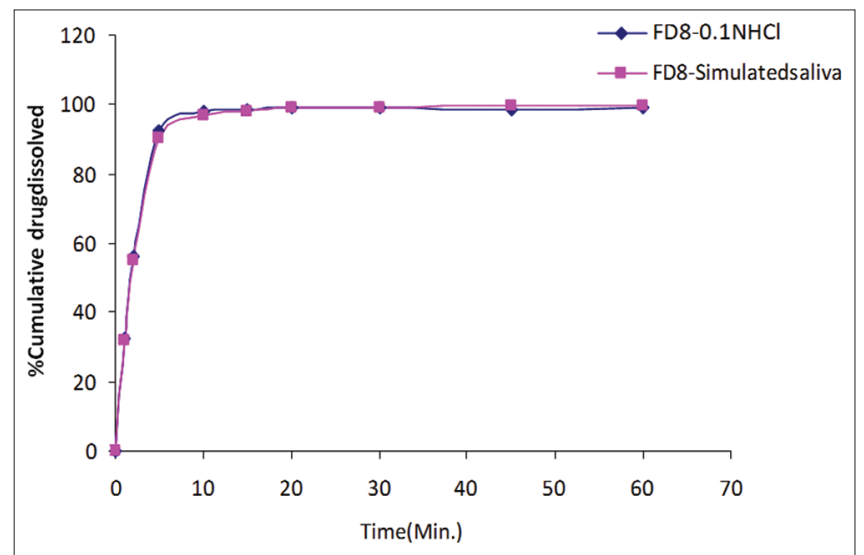

Figure 1: Dissolution profiles of batch FD8

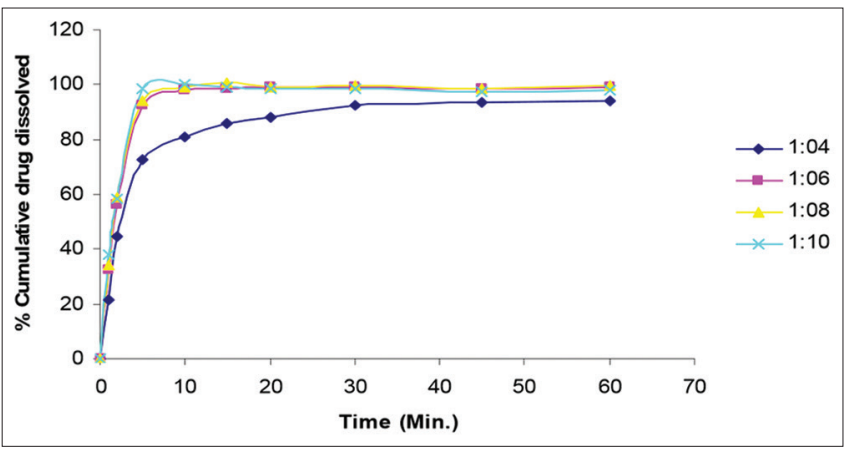

Figure 2: Dissolution profiles of different batches of fast dissolving films containing different drug:solubilizer ratio in $0.1 \mathrm{HCl}$

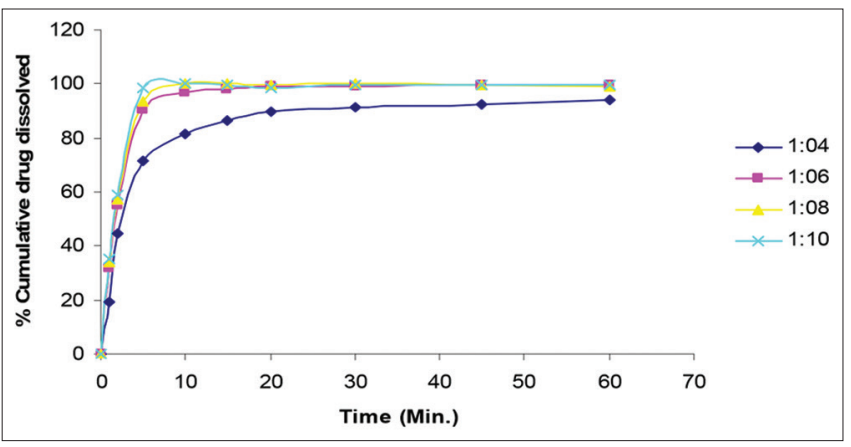

Figure 3: Dissolution profiles of different batches of fast dissolving films containing different drug:solubilizer ratio in simulated saliva

\section{Optimization of plasticizer concentration}

For the optimization of plasticizer concentration, three batches of backing layers with varied concentration $(5,10$, and $15 \% \mathrm{w} / \mathrm{w}$ of polymer) of PEG 400 were prepared taking polymer combination PVA 14000:PVP K 30 (40:60). All three prepared batches were studied for the evaluation parameters, namely thickness, dissolution time, folding endurance, and tensile strength.

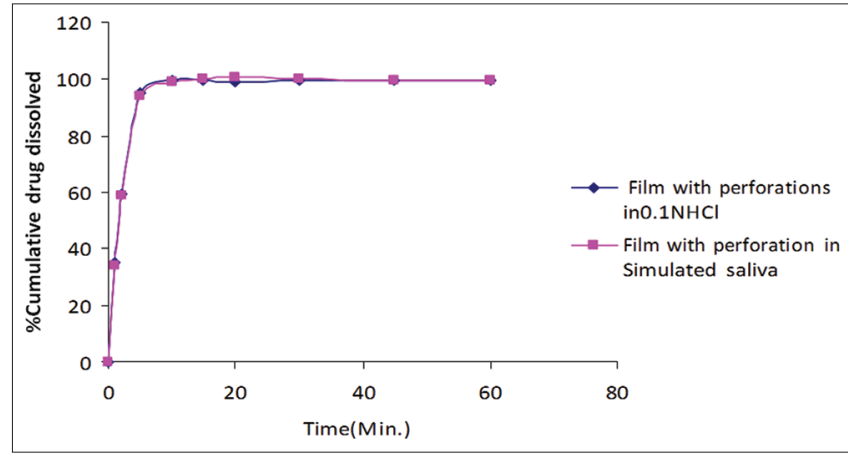

Figure 4: Dissolution profiles of fast dissolving oral film with perforations

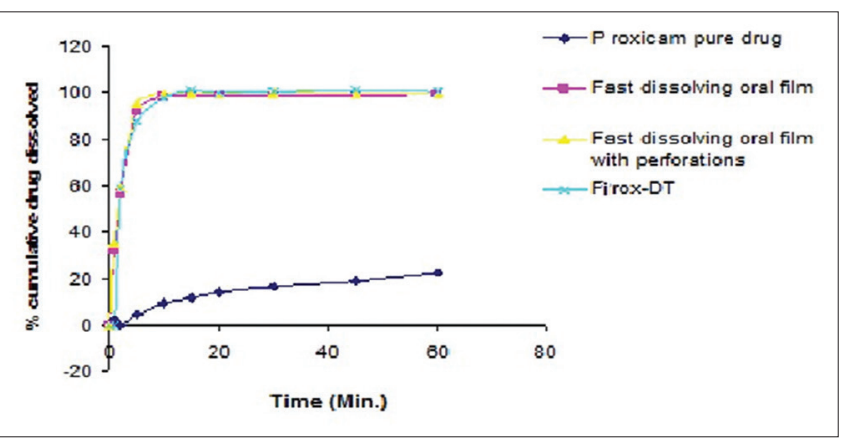

Figure 5: Comparative account of dissolution studies of piroxicam pure drug, fast dissolving oral film, fast dissolving oral film with perforations and marketed tablet formulation (Pirox DT)

Table 5: Hydration ratios of prepared backing layers Batch Hydration ratio with time

\begin{tabular}{lccc} 
& $\mathbf{1}(\boldsymbol{m i n})$ & $\mathbf{2}(\boldsymbol{m i n})$ & $\mathbf{5}(\mathbf{m i n})$ \\
\hline BL1 & 2.13 & 4.12 & 4.26 \\
BL2 & 1.94 & 3.87 & 3.79 \\
BL3 & 1.79 & 3.79 & 3.81 \\
BL4 & 2.02 & 4.29 & 4.31 \\
\hline
\end{tabular}

\section{Weight adjustment of backing layer}

Weight of backing layer (in relation to thickness) is of good concern from the point of view of its mechanical strength and dissolution time. For the weight adjustment, three different batches of backing layers were prepared having polymer ratio PVA 14000:PVP K 30 (40:60), and 5\% w/w PEG 400 as a plasticizer.

\section{Preparation and optimization of fast dissolving drug layer}

\section{Selection of water-soluble carriers for formulation of fast dissolving drug layer}

For selection of appropriate water-soluble carriers that have good solubilizing capacities for piroxicam the solubilities 
Table 6: Folding endurance, tensile strength, and mean thickness of the prepared backing layers

\begin{tabular}{lccc} 
Backing layers batch & Folding endurance (numbers) & Tensile strength $\left(\mathbf{K g} / \mathbf{c m}^{2}\right)$ & Mean thickness $(\boldsymbol{\mu m})$ \\
\hline BL1 & $>300$ & 1.12 & 20 \\
BL2 & $>300$ & 1.03 & 10 \\
BL3 & $>300$ & 0.98 & 10 \\
BL4 & $>300$ & 0.97 & 10 \\
\hline
\end{tabular}

Table 7: Evaluation of backing layers containing different plasticizers

\begin{tabular}{lclcccc}
$\begin{array}{l}\text { Backing } \\
\text { layers }\end{array}$ & $\begin{array}{c}\text { Polymer ratio PVA } \\
\mathbf{1 4 0 0 0 :} \text { PVP K } \mathbf{3 0}\end{array}$ & $\begin{array}{l}\text { Plasticizer } \\
(\mathbf{1 0 \%} \text { w/w) }\end{array}$ & $\begin{array}{c}\text { Mean } \\
\text { thickness }(\boldsymbol{\mu m})\end{array}$ & $\begin{array}{c}\text { Dissolution } \\
\text { time }(\mathbf{s})\end{array}$ & $\begin{array}{c}\text { Folding } \\
\text { endurance }(\mathbf{n u m b e r s})\end{array}$ & $\begin{array}{c}\text { Tensile strength } \\
\left.(\mathbf{K g} / \mathbf{c m})^{2}\right)\end{array}$ \\
\hline BL7 & $40: 60$ & Glycerin & 10 & 60 & $>300$ & 0.91 \\
BL8 & $40: 60$ & PG & 10 & 55 & $>300$ & 0.97 \\
BL9 & $40: 60$ & PEG 400 & 10 & 45 & $>300$ & 0.98
\end{tabular}

Where, PG: propylene glycol, PVA: Polyvinyl alcohol, PVP: Polyvinylpyrrolidone, PVA: Polyvinyl alcohol

Table 8: Evaluation of backing layers containing different concentrations of PEG 400

\begin{tabular}{|c|c|c|c|c|c|c|}
\hline $\begin{array}{l}\text { Backing } \\
\text { layers }\end{array}$ & $\begin{array}{c}\text { Polymer ratio PVA } \\
\text { 14000: PVP K } 30\end{array}$ & $\begin{array}{c}\text { PEG } \\
400(\% w / w)\end{array}$ & $\begin{array}{c}\text { Mean } \\
\text { thickness }(\mu \mathrm{m})\end{array}$ & $\begin{array}{l}\text { Dissolution } \\
\text { time (s) }\end{array}$ & $\begin{array}{c}\text { Folding } \\
\text { endurance } \\
\text { (numbers) }\end{array}$ & $\begin{array}{c}\text { Tensile strength } \\
\left(\mathrm{Kg} / \mathrm{cm}^{2}\right)\end{array}$ \\
\hline BL10 & $40: 60$ & 5 & 10 & 60 & $>300$ & 0.98 \\
\hline BL11 & $40: 60$ & 10 & 10 & 55 & $>300$ & 0.97 \\
\hline BL12 & $40: 60$ & 15 & 10 & 45 & $>300$ & 0.91 \\
\hline
\end{tabular}

PVA: Polyvinyl alcohol, PVP: Polyvinylpyrrolidone, PVA: Polyvinyl alcohol

\begin{tabular}{|c|c|c|c|c|c|c|}
\hline $\begin{array}{l}\text { Backing } \\
\text { layer }\end{array}$ & $\begin{array}{c}\text { Polymer ratio PVA } \\
\text { 14000: PVP K } 30\end{array}$ & $\begin{array}{c}\text { Mean } \\
\text { thickness }(\mu \mathrm{m})\end{array}$ & $\begin{array}{l}\text { Weight per } \\
6 \mathrm{~cm}^{2}(\mathrm{mg})\end{array}$ & $\begin{array}{l}\text { Dissolution } \\
\text { time (s) }\end{array}$ & $\begin{array}{c}\text { Folding endurance } \\
\text { (numbers) }\end{array}$ & $\begin{array}{c}\text { Tensile strength } \\
\left(\mathrm{Kg} / \mathrm{cm}^{2}\right)\end{array}$ \\
\hline BL13 & $40: 60$ & 10 & 10 & 45 & $>300$ & 0.80 \\
\hline BL14 & $40: 60$ & 10 & 15 & 48 & $>300$ & 0.93 \\
\hline BL15 & $40: 60$ & 10 & 20 & 60 & $>300$ & 0.97 \\
\hline
\end{tabular}

PVA: Polyvinyl alcohol, PVP: Polyvinylpyrrolidone, PVA: Polyvinyl alcohol

of piroxicam in aqueous blends containing different compositions from among different solubilizers such as sodium benzoate, sodium acetate, sodium citrate, urea and niacinamide, glycerin, propylene glycol, PEG 200, PEG 300, PEG 400, and PEG 600, and PVP K 30 were measured keeping total concentration of solubilizers constant $40 \% \mathrm{~W} / \mathrm{v}$. An excess amount of piroxicam was added to $5 \mathrm{ml}$ of these solutions in volumetric flasks, and the volumetric flasks were shaken on mechanical shaker for $12 \mathrm{~h}$ so that equilibrium solubility can be achieved and solutions were allowed undisturbed to equilibrate for $24 \mathrm{~h}$. Then, solutions were centrifuged at $2000 \mathrm{rpm}$ for $5 \mathrm{~min}$ in a centrifuge (Eppendorf) and then, solutions were filtered through Whatman grade 41 filters. Aliquots were suitably diluted with DM water and analyzed using UV spectrophotometer at $358 \mathrm{~nm}$ against corresponding reagent blanks.

\section{Preparation of fast dissolving drug layer}

All solubilizers [Table 11] except the drug were weighed accurately and transferred in a $100 \mathrm{ml}$ beaker. Then, minimum quantity of warm, demineralized water sufficient to dissolve the solubilizers was added (lesser the amount of water lesser will be the time required to evaporate it and chemical stability of drug may not be affected adversely during removal of water). Dissolution of the solubilizers was facilitated by agitation of a Teflon coated magnetic rice bead on a high-speed magnetic stirrer. After complete dissolution of solubilizers, $200 \mathrm{mg}$ of piroxicam was dissolved in the above solution, and temperature was maintained in the range of $55-60^{\circ} \mathrm{C}$ so as to facilitate the evaporation of water. As evaporation proceeded, the speed of rice bead automatically decreased, and it stopped stirring when most of the water was 
Chaklan, et al.: Development of oral film of piroxicam using mixed solvency concept

\begin{tabular}{lcccc}
\multicolumn{4}{c}{ Table 10: Equilibrium solubility of piroxicam in different aqueous blends of solubilizers } \\
$\begin{array}{l}\text { Blends of } \\
\text { solubilizers }\end{array}$ & Total concentration (\% w/v) & Solubilizer ratio & Solubility $(\%$ w/v) & $\begin{array}{c}\text { Solubility enhancement } \\
\text { ratio }\end{array}$ \\
\hline PVP+P2+SB & 40 & $13.3: 13.3: 13.3$ & 1.518 & 225.026 \\
PVP+P3+SB & 40 & $13.3: 13.3: 13.3$ & 1.291 & 191.351 \\
PVP+P4+SB & 40 & $13.3: 13.3: 13.3$ & 1.533 & 227.175 \\
PVP+P6+SB & 40 & $13.3: 13.3: 13.3$ & 1.298 & 192.426 \\
\hline
\end{tabular}

Where, SB: Sodium benzoate, P2: PEG 200, P3: PEG 300, P4: PEG 400, P6: PEG 600 and PVP: PVP K 30

\begin{tabular}{lcccc}
\multicolumn{5}{c}{ Table 11: Composition of different fast dissolving } \\
drug layers \\
Batch & \multicolumn{4}{c}{ Compositions } \\
\cline { 2 - 5 } & $\begin{array}{c}\text { Piroxicam } \\
\text { (mg) }\end{array}$ & $\begin{array}{c}\text { Sodiumbenzoate } \\
\text { ( } \mathbf{m g})\end{array}$ & $\begin{array}{c}\text { PEG } \\
\mathbf{4 0 0} \text { ( } \mathbf{m g})\end{array}$ & $\begin{array}{c}\text { PVP K } \\
\mathbf{3} \mathbf{m})\end{array}$ \\
\hline FD1 & 200 & 100 & 250 & 850 \\
FD2 & 200 & 100 & 300 & 800 \\
FD3 & 200 & 100 & 350 & 750 \\
FD4 & 200 & 150 & 250 & 800 \\
FD5 & 200 & 150 & 300 & 750 \\
FD6 & 200 & 150 & 350 & 700 \\
FD7 & 200 & 200 & 250 & 750 \\
FD8 & 200 & 200 & 300 & 700 \\
FD9 & 200 & 200 & 350 & 650 \\
FD10 & 200 & 250 & 250 & 700 \\
FD11 & 200 & 250 & 300 & 650 \\
FD12 & 200 & 250 & 350 & 600 \\
FD13 & 200 & 300 & 250 & 650 \\
FD14 & 200 & 300 & 300 & 600 \\
FD15 & 200 & 300 & 350 & 550 \\
\hline
\end{tabular}

PVP: Polyvinylpyrrolidone, PVA: Polyvinyl alcohol

evaporated. Then, this viscous mass was poured on already prepared backing layer in Petri plate and spread with a spreader. The prepared film was dried in an oven at $40^{\circ} \mathrm{C}$ for $24 \mathrm{~h}$. The prepared films were kept in desiccators and used for further studies.

\section{Evaluation of bilaminated fast dissolving oral film}

\section{Drug content}

The prepared fast dissolving oral films equivalent to $10 \mathrm{mg}$ of piroxicam $\left(6 \mathrm{~cm}^{2}\right)$ were accurately taken and transferred to a 500-ml volumetric flask. Approximately $300 \mathrm{ml}$ of DM water was added, and flask was shaken to dissolve the film completely, and the volume was made up to the mark with DM water. Then, the solution was filtered through Whatman grade 41 filter paper and analyzed spectrophotometrically (Shimadzu A-160) at $358 \mathrm{~nm}$ against corresponding reagent blank. The analysis was carried out in triplicate, and drug contents were determined.

\section{In vitro dissolution rate study}

Films containing $10 \mathrm{mg}$ of piroxicam were used in the in vitro dissolution study. Dissolution studies were conducted in modified USP XXIII apparatus (paddle over disk) at $50 \mathrm{rpm}$, using $900 \mathrm{ml}$ of $0.1 \mathrm{~N} \mathrm{HCl}$ and $300 \mathrm{ml}$ of simulated saliva fluid ( $2.38 \mathrm{~g} \mathrm{Na}_{2} \mathrm{HPO}_{4}, 0.19 \mathrm{~g} \mathrm{KH}_{2} \mathrm{PO}_{4}$, and $8.00 \mathrm{~g} \mathrm{NaCl}$ per liter of aqueous solution adjusted with phosphoric acid to $\mathrm{pH} 6.8$ ) as dissolution media. The temperature was maintained at 37 $\pm 0.5^{\circ} \mathrm{C} .10 \mathrm{ml}$ sample was withdrawn at regular intervals and analyzed spectrophotometrically (Shimadzu A-160) at $333 \mathrm{~nm}$ (where dissolution media were $0.1 \mathrm{~N} \mathrm{HCl}$ ) and at $358 \mathrm{~nm}$ (where dissolution media were simulated saliva of $\mathrm{pH}$ 6.8). An equal amount of fresh dissolution media was replaced immediately after withdrawal of sample.

\section{Uniformity of thickness}

Thickness of each prepared film sample was measured.

\section{Determination of hydration ratio}

Hydration ratios of prepared fast dissolving oral films were determined.

\section{Tensile strength}

Tensile strength of prepared fast dissolving oral films was measured.

\section{Folding endurance}

Folding endurance of prepared fast dissolving oral films was measured.

The mean values of three readings and standard deviations were shown in Table 13.

\section{Effect of perforations on drug dissolution rate of piroxicam from the bilaminated fast dissolving film}

To study the effect of perforations on the drug dissolution from fast dissolving oral film, perforations were made on a bilaminated oral film containing formulation FD8, making 
two perforations per $\mathrm{cm}^{2}$ using 16-gauge needle. Drug content of the film was determined as perforations may cause the loss of some drug. Dissolution study was conducted taking films containing $10 \mathrm{mg}$ of piroxicam in modified USP XXIII apparatus (paddle over disk) at $50 \mathrm{rpm}$, using $900 \mathrm{ml}$ SGF and $300 \mathrm{ml}$ simulated saliva fluid $\left(2.38 \mathrm{~g} \mathrm{Na}_{2} \mathrm{HPO}_{4}\right.$, $0.19 \mathrm{~g} \mathrm{KH}_{2} \mathrm{PO}_{4}$, and $8.00 \mathrm{~g} \mathrm{NaCl}$ per liter of aqueous solution

\section{Table 12: Drug content of piroxicam in bilaminated} fast dissolving oral film

\begin{tabular}{|c|c|c|c|c|}
\hline \multirow[t]{2}{*}{$\begin{array}{l}\text { Fast dissolving } \\
\text { drug layer batch }\end{array}$} & \multirow[t]{2}{*}{$\begin{array}{l}\text { Drug content } \\
\left(\mathrm{mg} / 6 \mathrm{~cm}^{2}\right)\end{array}$} & \multicolumn{3}{|c|}{$\begin{array}{l}\text { Hydration ratio } \\
\text { with time (min) }\end{array}$} \\
\hline & & 1 & 2 & 5 \\
\hline FD1 & 10.083 & 2.13 & 4.12 & 4.26 \\
\hline FD2 & 9.866 & 1.94 & 3.87 & 3.79 \\
\hline FD3 & 9.600 & 1.79 & 3.79 & 3.81 \\
\hline FD4 & 9.999 & 2.02 & 4.29 & 4.31 \\
\hline FD5 & 10.241 & 1.93 & 3.95 & 3.74 \\
\hline FD6 & 9.805 & 1.74 & 3.54 & 3.70 \\
\hline FD7 & 10.241 & 2.31 & 4.11 & 4.06 \\
\hline FD8 & 9.842 & 1.98 & 3.73 & 3.75 \\
\hline FD9 & 10.108 & 1.69 & 3.62 & 3.71 \\
\hline FD10 & 9.854 & 1.49 & 3.45 & 3.51 \\
\hline FD11 & 9.805 & 1.51 & 3.24 & 3.31 \\
\hline FD12 & 10.253 & 1.32 & 3.20 & 3.31 \\
\hline FD13 & 9.842 & 1.22 & 3.42 & 3.41 \\
\hline FD14 & 9.926 & 1.29 & 3.29 & 3.22 \\
\hline FD15 & 10.023 & 1.23 & 3.32 & 3.10 \\
\hline
\end{tabular}

adjusted with phosphoric acid to $\mathrm{pH} 6.8$ ) as dissolution media. The temperature was maintained at $37 \pm 0.5^{\circ} \mathrm{C} .10 \mathrm{ml}$ samples were withdrawn at regular intervals and analyzed spectrophotometrically (Shimadzu A-160) at $333 \mathrm{~nm}$ (when dissolution medium was $0.1 \mathrm{~N} \mathrm{HCl}$ ) and at $358 \mathrm{~nm}$ (when dissolution medium was simulated saliva $\mathrm{pH}$ 6.8). An equal amount of fresh dissolution media was replaced immediately after withdrawn of the sample.

\section{RESULTS AND DISCUSSION}

On the basis of solubility studies, the blend containing PVP14000 + PEG $400+$ SB in the ratio of 13.3:13.3:13.3 shown the highest solubility enhancement, and therefore, combination of these three solubilizers were selected to form the fast dissolving drug layer because of low individual toxicity of solubilizer and achieved desired required solubility of drug described in Table 10. For formulation development, backing layer of composition BL4 containing polymer ratio PVA 14000: PVP K 30 (40:60) was found to be most appropriate for the desired properties. Hence, the polymeric ratio PVA 14000:PVP K 30 (40:60) was taken as optimized polymer ratio on the basis of mechanical properties and disintegration time of backing layer as described in Tables 2-6. PEG 400 provides faster dissolution of the prepared backing layer as well as better tensile strength. PEG $4005 \% \mathrm{w} / \mathrm{w}$ was taken as the optimized concentration of plasticizer. As described in Tables 7 and 8, the backing layer prepared of weight $15 \mathrm{mg}$ per $6 \mathrm{~cm}^{2}$ was found to be most appropriate for the desired properties as described in Table 9. For the preparation and optimization of fast dissolving film layer, fast dissolving drug layer of 15 formulae [Table 11] was prepared keeping

\begin{tabular}{|c|c|c|c|}
\hline Backing layer & Folding endurance (numbers) & Tensile strength $\left(\mathrm{Kg} / \mathrm{cm}^{2}\right)$ & Mean thickness $(\mu \mathrm{m})$ \\
\hline FD1 & 72 & 1.24 & 60 \\
\hline FD2 & 126 & 1.13 & 60 \\
\hline FD3 & 163 & 1.06 & 70 \\
\hline FD4 & 69 & 1.21 & 60 \\
\hline FD5 & 112 & 1.11 & 60 \\
\hline FD6 & 139 & 1.02 & 70 \\
\hline FD7 & 65 & 1.20 & 70 \\
\hline FD8 & 106 & 1.12 & 70 \\
\hline FD9 & 125 & 1.00 & 70 \\
\hline FD10 & 22 & 1.21 & 70 \\
\hline FD11 & 49 & 1.09 & 70 \\
\hline FD12 & 65 & 0.98 & 70 \\
\hline FD13 & 16 & 1.15 & 70 \\
\hline FD14 & 1 & 1.08 & 70 \\
\hline FD15 & 22 & 0.92 & 70 \\
\hline
\end{tabular}


Table 14: Evaluation of different batches of fast dissolving oral films

\begin{tabular}{lcccc}
\multicolumn{4}{c}{ Table 14: Evaluation of different batches of fast dissolving oral films } \\
Batch & Drug: solubilizer ratio & Mean thickness $(\boldsymbol{\mu m})$ & Folding endurance (numbers) & Tensile strength $\left(\mathbf{K g} / \mathbf{c m}^{2}\right)$ \\
\hline FD 16 & $1: 4$ & 50 & 122 & 0.98 \\
FD 8 & $1: 6$ & 70 & 106 & 1.12 \\
FD 17 & $1: 8$ & 80 & 91 & 1.21 \\
FD 18 & $1: 10$ & 110 & 72 & 1.32 \\
\hline
\end{tabular}

\begin{tabular}{|c|c|c|c|c|}
\hline \multirow[t]{2}{*}{ Batch } & \multirow[t]{2}{*}{ Drug: solubilizer ratio } & \multicolumn{3}{|c|}{$\begin{array}{l}\text { Hydration ratio } \\
\text { with time (min) }\end{array}$} \\
\hline & & 1 & 2 & 5 \\
\hline FD 16 & $1: 4$ & 2.35 & 5.23 & 5.31 \\
\hline FD 8 & $1: 6$ & 1.98 & 3.73 & 3.75 \\
\hline FD 17 & $1: 8$ & 1.34 & 3.05 & 2.91 \\
\hline FD 18 & $1: 10$ & 1.12 & 2.88 & 2.70 \\
\hline
\end{tabular}

the ratio of drug:solubilizers always, 1:6 and evaluated for their film properties and dissolution rate described in Tables 11-15. Among the 15 batches, FD 8 batch showed better evaluation results and was taken as the optimized batch. Dissolution profile of batch FD8 was presented in Figure 1. Dissolution studies of prepared fast dissolving oral film revealed that drug dissolution from fast dissolving oral film containing drug:solubilizer ratio 1:6 showed good folding endurance among all the prepared fast dissolving oral films. Hence, the 1:6 drug:solubilizers ratio was considered as optimized. Comparative dissolution profiles are shown in Figures 2-4. Effect of perforations (in the prepared film) on the dissolution of piroxicam from prepared film was also determined, and dissolution profiles of piroxicam pure drug, optimized fast dissolving oral film, fast dissolving oral film with perforations, and marketed dispersible tablet (Pirox DT) were compared in Figure 5. Results showed that dissolution rate of piroxicam from fast dissolving oral film was similar to marketed dispersible tablet (Pirox DT).

\section{CONCLUSION}

From all the above studies, it was concluded that the approach of mixed solvency is novel, safe, cost-effective, and userfriendly. It also eliminates the problem of toxicity associated with high concentration of single solubilizers. Hence, it may be employed in dosage form development of drugs where a fast onset of action is desired. It may also enhance the bioavailability associated with poor dissolution of the drug.

\section{REFERENCES}

1. Arya A, Chandra A, Sharma V, Pathak K. Fast dissolving oral film: an innovative drug delivery system and dosage form, International Journal of Chem Tech Research, 2010; 2(1): 576-583.

2. Leung SH, Spence L, Robert S, Kumar LD, Kulkarni N, Sorg AF. Fast Dissolving Orally Consumable Films. US: US Patent 7491406; 2009.

3. Satishbabu BK, Srinivasan BP. Preparation and evaluation of buccoadhesive films of atenolol. Indian J Pharm Sci 2008;70:175-9.

4. Cilurzo F, Cupone IE, Minghetti P, Selmin F, Montanari L. Fast dissolving films made of maltodextrins. Eur J Pharm Biopharm 2008;70:895-900.

5. Friend DR, Levine AW, Ziegler KL, Manna E. Fast Dissolving Films for Oral Administration of Drugs. US: US Patent Application No. 20040208931; 2004.

6. Thakur N, Bansal M, Sharma N, Yadav G, Khare P. Overview on "a novel approach of fast dissolving films and their patents", Advances in Biological Research, 2013;7(2):50-58.

7. Maheshwari RK. Mixed-solvency-a novel concept for solubilization of poorly water-soluble drugs. J Technol Eng Sci 2009;1:39-44.

8. Maheshwari RK. Potentiation of solvent character by mixed-solvency concept: a novel concept of solubilization. J Pharm Res 2010;3:411-3.

9. Maheshwari RK. Solubilization of ibuprofen by mixedsolvency approach. Indian Pharm 2009;87:81-4.

10. Maheshwari RK. Mixed solvency approach boon for solubilization of poorly water-soluble drugs. Asian J Pharm 2010;1:60-3.

11. Jain R, Maheshwari RK, George P. Formulation development and evaluation of controlled release tablets of lamotrigine using mixed solvency concept. Bull Pharm Res 2015;5:9-14.

12. Patel SK, Maheshwari RK. Formulation development and evaluation of SEDDS of poorly soluble drug made by novel application of mixed-solvency concept. Int $\mathrm{J}$ Pharm Res 2012;4:51-6.

13. Shilpkar R, Maheshwari RK. Formulation development and evaluation of injection of poorly soluble drug using mixed solvency concept. Int $\mathrm{J}$ Pharm Bio Sci2012;3:179-89.

14. Agarwal S, Maheshwari RK.Formulation development and evaluation of in situ nasal gel of poorly watersoluble drug using mixed solvency concept. Asian J Pharm 2011;5:131-40.

15. Karwande VK, Maheshwari RK. Application of novel concept of mixed-solvency in the design and development of floating microspheres of furosemide. Int 
J Pharm Pharm Sci 2013;5:167-75.

16. Chandna C, Maheshwari RK. Mixed solvency concept in reducing surfactant concentration of self-emulsifying drug delivery system of candesartan cilexetil using D-optimal mixture design. Asian J Pharm 2013;7:83-91.

17. Soni LK, Solanki SS, Maheshwari RK. Studies on mixed solvency concept in formulation development of oral solution (syrup) of poorly water soluble drugs. J Harmon Res Pharm 2015;4:305-15.

18. Soni LK, Solanki SS, Maheshwari RK Solubilization of poorly water-soluble drug using mixed solvency approach for aqueous injection. $\mathrm{Br} \mathrm{J}$ Pharm Res 2014;4:549-68.

19. Jain DK, Patel VK, Bajaj S, Jain N, Maheshwari RK. Novel approach for spectrophotometric estimation of solid dosage forms of tinidazole using solids (eutectic liquid of phenol and niacinamide) as solubilizing agent (mixed solvency concept). World J Pharm Pharm Sci 2015;4:763-9.

20. Yash M, Mishra DK, Mahajan SC, Prachi M, Maheshwari RK, Jain V. Novel pharmaceutical application of mixed solvency in the formulation development of syrups (liquid oral solutions) of poorly water-soluble drugs. Int J Pharm 2013;3:753-8.

21. Tomar A, Sharma K, Chauhan NS, Mittal A. Formulation and evaluation of fast dissolving oral film of dicyclomine as potential route of buccal delivery. Int J Drug Dev Res 2012;4:408-17.

22. Maheshwari RK, Putiwala M, Padiyar A. Novel approach for spectrophotometric estimation of naproxen in tablet dosage form using solids(eutectic liquid of phenol and niacinamide) as solubilizing agent (mixed solvency concept). Asian J Pharm Res 2015;5:25-8.

23. Maheshwari RK, George P, Fouzdar A, Singh S. "Solid as Solvent" - novel approach for spectrophotometric analytical technique for nalidixic acid tablets using solids (eutectic liquid of phenol and metformin hydrochloride) as solubilizing agents (Mixed Solvency Concept). Int J Pharm Chem Anal 2015;2:42-5.

24. Maheshwari RK, Jain P, Parkh D. Solid as solventnovel technique for spectrophotometric estimation of naproxen tablets using solids (eutectic liquid of phenol and metformin hydrochloride) as solubilizing agents (mixed solvency concept). Eur J Biomed Pharm Sci 2015;2:1011-8.

25. Solanki SS, Soni LK, Maheshwari RK. Solid as solventnovel spectrophotometric analytical technique for frusemide tablets using solids (eutectic liquid of phenol and niacinamide) as solubilizing agents (mixed solvency concept). Int J Adv Pharm Res 2015;6:147-50.

26. Shweta A, Maheshwari RK. Formulation development of in-situ nasal drug delivery system of poorly watersoluble drug (Indomethacin) using mixed solvency concept and their evaluation. Bull Pharm Med Sci 2014;2:2128-38.

27. Maheshwari RK, Prasad S, Pandey P, Wanare G. Novel spectrophotometric analysis of piroxicam tablets using ibuprofen sodium as hydrotropic solubilizing agents. Int J Pharm Sci Drug Res 2010;2:2102.

28. Ashish S, Maheshwari RK. Solid as solvent- novel spectrophotometric analytical technique for quantitative estimation of piroxicam tablets using solids (eutectic liquid of phenol and lignocaine hydrochloride) as solubilizing agents (mixed solvency concept). World J Pharm Res 2016;5:1560-7.

29. Maheshwari RK, Akash PS, Pandey LK, Gangrade A. Solid as solvent: Novel spectrophotometric analytical technique for quantitative analysis of tinidazole tablets using solids (eutectic liquid of phenol and metformin hydrochloride) as solubilizing agents (mixed solvency concept). Pharm Innov J 2016;5:1-2.

Source of Support: Nil. Conflict of Interest: None declared. 